\title{
The Highland Falls Brewery
}

\author{
MA255 Project, Spring 2013 \\ Due: Monday, 15 April 2013
}

\begin{abstract}
"Without question, the greatest invention in the history of mankind is beer. Oh, I grant you that the wheel was also a fine invention, but the wheel does not go nearly as well with pizza" (Disclaimer: Don't drink and drive. The legal drinking age is 21.)

-Dave Barry, New York Times Best Selling Author
\end{abstract}

\section{The Micro-Brewery/Background}

The Micro-Brewery, or craft brewery, is a small commercial beer brewery, usually limited to an output of a certain number of barrels per year. These breweries usually only distribute their product to a small region as opposed to the larger breweries who may distribute nationally or internationally.

Beer is made from a variety of ingredients, notably, malted barley, wheat, rye, hops, and water. The barley, wheat, or rye is "mashed" in order to convert the starches to sugar which is then "sparged" and "lautered" to remove the sugars from the rest of the grain (the husks). This combination of sugar and water is called "wort". The wort is then boiled to rid the liquid of any enzymes that may still be present. After boiling the wort for approximately one hour, it is then chilled before yeast is added. The yeast converts the sugars to alcohol, a process called "fermentation", in which the wort converts to beer. Hops are added for flavor either during the boiling stage or during the final stages of fermentation. Generally speaking, hops added towards the beginning of the boil add bitterness, while those added later add aroma.

\section{Project}

You will play the role of a consultant for company TEDAC who has been hired by a local entrepreneur who wishes to open a micro-brewery in Highland Falls. This entrepreneur would like for you to model the process of beer fermentation in order to help predict his operating costs and income. He would specifically like help in determining an optimal flavor of a particular type of beer which he hopes will be finalized for the class of 2016 upon their graduation from West Point. He wishes to set up his brewery with four 30 barrel fermentation 
vessels and wants to eventually have them operating continually. One beer barrel holds 31 gallons.

Task 1: Here we wish to create a rough model to determine the amount of alcohol by volume $(\mathrm{ABV})$ in a batch of beer after a full fermentation cycle. We will assume that a full fermentation cycle lasts seven (7) days. First, we must create a simple model of beer fermentation, modeling the amount of sugar in the wort at any given time, dependent upon the initial amounts of sugar and yeast, and the ambient temperature. We will assume that the rate of change of the sugar is proportional to the amount of sugar at time $t$ multiplied by a growth constant, $r$. The growth constant is equal to the ambient temperature (in ${ }^{\circ} F$ ) multiplied by the initial amount of yeast divided by 70,000. The growth constant, $r$, is shown here:

$$
r=-\frac{\text { temp } \times \text { yeast }}{70,000}
$$

After we have created the rough model, we will calculate the approximate ABV, assuming it is directly proportional to the difference between the initial amount of sugar and the amount of sugar present in the beer at the end of a fermentation cycle. We will use the following formula to determine the amount of ABV in the beer at the end of fermentation ( $S$ is the amount of sugar in the wort (beer) with units of $\left[\mathrm{mol} / \mathrm{m}^{3}\right]$ and $t$ is in hours):

$$
A B V=0.00272\left(S_{0}-S\left(t_{\text {final }}\right)\right) .
$$

The yeast used in brewing is generally of two types: ale yeast, Saccharomyces cerevisiae, and lager yeast, Saccharomyces uvarum. The ale yeast performs best at a temperature of $70^{\circ} \mathrm{F}$, while lager yeast performs best at a temperature of $60^{\circ} \mathrm{F}$. We will be using these temperatures when considering the following questions.

a) Model verification: With values of $S_{0}=10$, yeast $=10$, temp $=70$, you should have an ending value of sugar of 1.86374. This should also correspond to an ABV of: 0.02213 .

b) If you started with 20 units of sugar, 15 units of yeast, at a temperature of $70^{\circ} \mathrm{F}$, what would your final ABV value be?

c) Assuming the same amounts as in the previous question but using a lager yeast strain $\left(t e m p=60^{\circ} \mathrm{F}\right)$, what would your final ABV be?

Task 2: In addition to the class of 2016 brew, the entrepreneur wishes to make a very strong grand opening brew with an ABV of 10\%. Use the model developed in Task 1 with a fermentation cycle of seven (7) days to answer the following questions for the entrepreneur.

a) What initial values of sugar and ale yeast would accomplish an ABV of about $10 \%$ ? Assume that the entrepreneur wishes to cap the initial amount of sugar to 60 units in order to capture the particular style of beer he is aiming for. 
b) What if he decides to use a lager yeast instead of an ale yeast? How does this change initial amount of sugar and yeast needed to get the correct ABV?

c) If he was limited to using 42 units of sugar and 10 units of lager yeast initially, how much longer (past seven days) would he have to wait until he reaches $10 \%$ ABV?

Task 3: A more complex model for modeling the fermentation of the sugars in beer has been created by Gee and Ramirez (1993). The entrepreneur is a distant relative of one of the authors and wants you to use their model in order to model the fermentation in his beer. The fermentation model accounts for the amount of yeast $(\mathrm{X}(\mathrm{t}))$ present in the beer and three different types of fermentables (glucose $(\mathrm{G}(\mathrm{t})$ ), maltose $(\mathrm{M}(\mathrm{t}))$ and maltotriose $(\mathrm{N}(\mathrm{t}))$ ). All units are in $\left[\mathrm{mol} / \mathrm{m}^{3}\right]$. Units for $\mu_{i}$ are in $\left[\mathrm{hrs}^{-1}\right]$ and $t$ is in [hrs]. One $\mathrm{m}^{3} \approx 264.17$ gallons [US]. Reference the Mathematica file "MA255_ProjectAY13-2(FORCADETS).nb" for this task.

The system of equations is:

$$
\begin{aligned}
& \frac{d G(t)}{d t}=-\mu_{1} X(t) \\
& \frac{d M(t)}{d t}=-\mu_{2} X(t) \\
& \frac{d N(t)}{d t}=-\mu_{3} X(t) \\
& \frac{d X(t)}{d t}=\left[0.134 \mu_{1}+0.268 \mu_{2}+0.402 \mu_{3}\right] X(t)
\end{aligned}
$$

where $\mu_{i}$ (for $\left.i=1,2,3\right)$ are growth rates and are defined as:

$$
\begin{aligned}
\mu_{1} & =\frac{\mu_{G} G(t)}{K_{G}+G(t)} \\
\mu_{2} & =\frac{\mu_{M} M(t)}{K_{M}+M(t)} \cdot \frac{K i_{G}}{K i_{G}+G(t)} \\
\mu_{3} & =\frac{\mu_{N} N(t)}{K_{N}+N(t)} \cdot \frac{K i_{G}}{K i_{G}+G(t)} \cdot \frac{K i_{M}}{K i_{M}+M(t)} .
\end{aligned}
$$

Specific parameter values are given in Table 1.

The entrepreneur wants to gain a better understanding of this model. You must explain the details of how each of the sugars (G, M, N) interact with each other and the yeast $(\mathrm{X})$ based on the model. Specifically, explain the effect of the inhibition constants for glucose $\left(K i_{G}\right)$ and maltose $\left(K i_{M}\right)$ and how they affect the overall behavior of the system. (Hint: Use the values given for the initial concentrations of glucose, maltose, maltotriose, yeast, and $t_{\max }$ in the Mathematica file and the corresponding plot to help describe the amount of sugar or yeast present). 


\begin{tabular}{|c|c|c|}
\hline growth rate for glucose & $\mu_{G}$ & 0.01348 \\
\hline growth rate for maltose & $\mu_{M}$ & 0.02581 \\
\hline growth rate for maltotriose & $\mu_{N}$ & 0.09881 \\
\hline Michaelis constant for glucose & $K_{G}$ & 0.7464 \\
\hline Michaelis constant for maltose & $K_{M}$ & 40.97 \\
\hline Michaelis constant for maltotriose & $K_{N}$ & 250.0 \\
\hline Inhibition constant for glucose & $K i_{G}$ & 5.356 \\
\hline Inhibition constant for maltose & $K i_{M}$ & 13.17 \\
\hline
\end{tabular}

Table 1: Model parameter values used by Gee and Ramirez (1993).

Task 4: In order to be profitable, he wishes to limit the fermentation process to only $\mathbf{1 0}$ days. For one particular beer that the entrepreneur wishes to produce, the desired flavor of the beer can be rated with a particular function that is dependent upon the initial values of the sugars present in the beer. The taste function is given by:

Taste $=5.89\left(G_{0}-G\left(t_{\max }\right)\right)+33.512\left(M_{0}-M\left(t_{\max }\right)\right)+10.1\left(N_{0}-N\left(t_{\max }\right)\right)-12.41 X_{0}-22.3 M_{0}$.

In order to keep the alcohol levels at a reasonable level, you must limit the total amount of sugar to 200 mols. (G, M, N are the values at the end of the 10 day period). Use the same model from Task 3 to answer the following questions, using an appropriate level of explanation:

a) What are the initial values of each sugar (in mols) that will give an optimal taste value?

b) What is the optimal taste value?

\section{Paper: Due 15 April 2013 (100 points)}

Write a paper that guides the reader through all of the processes you have completed. Doing the mathematics correctly is important, but it is also critical to be able to explain the mathematics that you have done, as well as analyze your results and reflect on their relevance in the real world. Before you begin writing, consider what you want your audience to gain from reading this paper.

The Project Write-up Guidance document found on the MA255 website should be used as general guidance. The main body should be approximately 5 - 10 pages in length (doublespaced and Times New Roman font, size 12). This length does NOT include any calculations, such as Mathematica files, which should also be submitted as well as organized appendices. 